\title{
TRAVIS BICKLE EM (RE)CONSTRUÇÃO NA ENUNCIAÇÃO FÍLMICA: UMA ANÁLISE DIALÓGICA DO SUJEITO PROTAGONISTA DE TAXI DRIVER (1976)
}

Lizandra Belarmino de Moura

\begin{abstract}
Resumo: Há uma urgência em se pensar o sujeito inserido em uma "malha bordada" por diversos discursos contraditórios em circulação, que, consequentemente reverberam em suas ações e, especialmente, em seus enunciados. Nesta pesquisa é analisado, descrito e interpretado enunciados verbovocovisuais eleitos a partir da narrativa fílmica de Taxi Driver (1976), de Martin Scorsese, com a finalidade de compreender como se dá a transformação e movimentação do sujeito Travis Bickle (Robert De Niro). Partindo, assim, da hipótese de que as relações dialógicas entre ele e os "outros" que o circundam são relevantes e reveladores para entender a construção da enunciação fílmica e, consequentemente, da construção/transformação desse sujeito. $\mathrm{O}$ aporte teórico e metodológico vem da teoria dialógica da linguagem do Círculo de Bakhtin. Assim, ao cotejar conceitos com os recortes de cenas feitos, compreendemos como se dá a construção do sujeito que é transpassado por seu contexto sócio-histórico e ideológico, enquanto reflete e refrata a sua realidade, pois traços de contrariedade foram percebidos nos discursos que permeiam Travis e isso porque, os enunciados são as arenas discursivas em que os discursos entram em conflito.
\end{abstract}

Palavras-chave: sujeito, diálogo, enunciado, enunciação fílmica, discursos.

\section{Introdução}

Pensando a partir das constantes (re)construções do sujeito na vida e dos possíveis elementos que permeiam os acontecimentos que o constitui, sendo eles muitas vezes explorados em obras fictícias, descreve-se, interpreta-se e analisa-se a enunciação fílmica de Taxi Driver (1976), de direção de Martin Scorsese e roteiro de Paul Schrader.

À vista disso, a hipótese que dá luz a esta pesquisa é de que o processo de composição da enunciação de Taxi Driver se dá pelo movimento dialógico do sujeito Travis Bickle com os demais personagens juntamente com a cidade de Nova Iorque da década de 1970 do século XX, devido à sua complexa problemática na estrutura social, política e ideológica; compactando assim, o espírito estadunidense de uma Nova Iorque que direciona seu preconceito para determinados grupos marginalizados (homossexuais, prostitutas, mendicantes, dependentes químicos, drag queens etc.), depositando sobre eles a culpa pela alta criminalidade, pela pobreza, pelas doenças e por outros problemas que a cidade comporta neste recorte de tempo.

Sendo assim, para o estudo da construção da enunciação em Taxi Driver, consideramos as diferentes posições de sujeito enunciador "seja na categoria do $\mathrm{eu}$ para-mim, seja na categoria do outro-para-mim" (BAKHTIN, 1997, p. 44; grifos do 
autor), marcando, consequentemente, uma posição exotópica entre arte e vida na esfera do enunciado. Nessa perspectiva, estudo a noção de enunciado como arena de lutas ideológicas na construção do sujeito Travis Bickle, ora como sujeito alienado, conservador e um vilão para as chamadas minorias, ora como sujeito herói, na enunciação fílmica de Taxi Driver. Quando considerada a enunciação fílmica, portanto, verbovocovisual $^{1}$, pondero estabelecer um recorte das cenas (microcorpus) que compõem o filme (macrocorpus) Taxi Driver para a análise neste estudo.

Nos recortes eleitos para análise, podemos visualizar o modo que o sujeito, na enunciação fílmica, reflete e refrata sua realidade, tanto em seus diálogos com os demais personagens da trama quanto para a imagem que ele tem (e consequentemente, nós espectadores podemos ter) da cidade de Nova Iorque, a partir do seu olhar pela janela de seu táxi. Realidade essa coincidente com a realidade de produção da narrativa fílmica, já que, segundo Lubin (2005, p. 9), "O filme [Taxi Driver], sem dúvida, refletiu as preocupações e a paranóia social dos anos 1970."2 Cenas como a denominada "Travis visits Betsy"3 (20min33s a 27min29s), à qual acontece o primeiro encontro entre Travis e Betsy (interpretada por Cybill Shepard) no gabinete da campanha presidencial de Palantine, onde ela trabalha e, em seguida, em uma lanchonete e outra cena que denominados de "Travis supports Palantine"4 (28min23s a 30min48s) em que Travis Bickle recebe como passageiro em seu táxi um dos candidatos à presidência dos Estados Unidos, o senador Charles Palantine (interpretado por Leonard Harris) são icônicas para visualizar as posições contraditórias do sujeito protagonista que correspondem à "paranóia" compreendida por Lubin e que também, ao partirem do sujeito enunciador, denunciam a ele mesmo para nós.

Além da perspectiva bakhtiniana da linguagem, que por si só dialoga com outras áreas de conhecimento fora do campo linguístico como a Sociologia, a Filosofia e a Psicanálise, por exemplo, apoio-me em alguns autores. Primeiramente, Hall (2015) com seus sujeitos sociológico e pós-moderno. O seu conceito de sujeito-sociológico dialoga com a tese empregada pelo Círculo Bakhtiniano de que, é no processo interação verbal que se dá a formação da identidade de um indivíduo: “a identidade é formada na

\footnotetext{
1 A partir da descrição verbal podemos interpretar e analisar os enunciados verbovocovisuais da enunciação de Taxi Driver, portanto, consideramos a parte descritiva da transcrição dos enunciados salutar para se tratar do que é vocal (entonação, voz, tom, ritmo, por exemplo) e do que é visual (a construção cênica formada pelas imagens que compõem o todo arquitetônico do filme em estudo).

2 Tradução nossa. No original, em inglês: "The film undoubtedly mirrored the concerns and social paranoia of the 1970s."

3 Tradução para o português: "Travis visita Betsy" (tradução nossa).

4 Tradução para o português: "Travis apoia Palantine" (tradução nossa).

CSOnline - Revista Eletrônica de Ciências Sociais, Juiz de Fora, n. 24 (2017) Dez., pp. 1-309.
} 
‘interação' entre o 'eu' e a sociedade” (HALL, 2015, p. 11); por outro lado, o sujeito pós-moderno corresponde, ainda dialogando com Bakhtin, na tese sobre uma espécie de heterogeneidade na formação da identidade dos sujeitos, uma vez que, exposto a variedades limitadas de discursos, esse sujeito torna-se relativamente instável: "O sujeito [...] está se tornando fragmentado; composto não de uma única, mas de várias identidades, algumas vezes contraditórias ou não resolvidas.” (HALL, 2015, p. 11) Travis comporta essas peculiaridades em sua identidade: a influência dos "outros" em sua constituição e seus traços de contrariedade.

Em segundo lugar, apoio-me em Simmel (1973) com seu conceito de "atitude blasé", que representa alguns dos posicionamentos de Travis, já que para o autor não há, possivelmente, um fenômeno psíquico incondicionalmente reservado à metrópole. A personagem protagonista age de maneira bastante contraditória, uma vez que, expressa desprezo por certos grupos sociais da cidade de Nova Iorque, uma certa apatia em relação à vida em um contexto prático e existencial (sentimento esse oriundo de um estilo de vida urbano) mas também se posiciona a fim de resolver, ao seu modo, o que ele entende que deva ser "corrigido". a fim de fundamentar e ilustrar os impactos da vida urbana sob o indivíduo e o quanto questões intrínsecas à condição de um sujeito histórico e social influenciam em obras de arte. Uma vez que a criação artística, sendo fruto da criatividade humana, está nela e para ela (BAKHTIN, VOLOSHINOV, 1976).

Quando consideramos que ao enunciar o sujeito se denuncia, entendemos que tudo o que é enunciado possui um lugar de dizer que dá acabamento à enunciação; é sob essa perspectiva da relação dialógica entre sujeitos e enunciados que estudamos em Taxi Driver a partir de sua enunciação. Assim sendo, elegi duas cenas que acontecem na ordem cronológica da narrativa fílmica, a começar por "Travis visits Betsy" e, por conseguinte, "Travis Supports Palantine". Acreditamos que estas cenas nos dão pistas significativas do movimento dialógico do sujeito Travis na enunciação fílmica para o desenvolvimento da pesquisa, uma vez que enquanto sujeito dialógico-ideológico na relação com os outros - aqui, Betsy e o senador Palantine - acontece o processo contínuo de construção e transformação do sujeito Travis dentro da enunciação fílmica em estudo.

\section{O diálogo como revelador da identidade do sujeito}

Um discurso, ao ser pronunciado, ou seja, materializado, passa por uma série de processos de ressignificação e, mesmo depois de ser materializado, esse processo de CSOnline - Revista Eletrônica de Ciências Sociais, Juiz de Fora, n. 24 (2017) Dez., pp. 1-309. 
ressignificação apresenta-se de modo contínuo, especialmente, porque todo discurso tem sua realização única, singular. Nesse sentido, entendemos que todo e qualquer enunciado possui um lugar de dizer, juntamente com a maneira à qual foi materializado, tal seja, seu tom de enunciação. Por essa razão, ao analisar recortes de cenas de uma enunciação fílmica, é necessário que se retorne a outras cenas que possam auxiliar a compreensão da ação dialógica do sujeito foco do estudo, composta por suas movimentações e transformações em relação a si-mesmo e na interação com os outros. Por meio desse diálogo que se instaura na enunciação fílmica, conseguimos visualizar as marcas enunciativas do sujeito enunciador.

Considero analisar a personagem Travis, o sujeito protagonista da obra cinematográfica em estudo, a partir das relações dialógicas que ele estabelece com outras personagens, de modo a demonstrar o funcionamento do diálogo na enunciação fílmica de Taxi Driver. A interação do sujeito com os outros é a arena que nos permite observar os posicionamentos ideológicos que se instauram na arquitetônica fílmica, uma vez que "toda palavra é ideológica" (BAKHTIN; VOLOCHÍNOV, 2009, p. 126). Logo, ao enunciar, os sujeitos em estudo denunciam em quais grupos sociais se filiam, permitindo ainda ao sujeito Travis se reconhecer perante o corpo social.

Além disso, questionamos e refletimos sobre quem ou o quê, onde e quando o nosso sujeito enuncia, pois seus enunciados revelam muito de si, pelo o que diz e pelo o que deixa de dizer, como também o modo do enunciado se concretizar. Para isso, tomamos como exemplo um fragmento da cena a ser analisada a seguir.

Neste trecho em que Travis, ao expressar para Betsy suas impressões sobre ela, é possível de se observar o fenômeno de definição que o próprio "eu" de Travis se deixa revelar ao mesmo tempo que expõe o de sua interlocutora:

21min52s a 22min25s [Travis para Betsy] - Acho que você é uma pessoa solitária. Eu passo muito aqui e a vejo. Vejo você cercada de gente... e vejo telefones, a mesa cheia de coisas... que não significam nada. E quando entrei e falei com você... vi nos seus olhos, no seu jeito... que você não é feliz. E acho que precisa de alguma coisa. Se quiser chamar de amigo, pode chamar. ${ }^{5}$

Podemos afirmar isso, pois, Travis ao reconhecer a solidão de Betsy reconhece e está reconhecendo a sua própria, além de sua infelicidade, já que só é possível reconhecer no outro aquilo que em nós, a priori, existe. Do contrário, isso passaria despercebido. É importante salientar que, sentimentos como esses exprimem-se em

\footnotetext{
5 Tradução via legendas retiradas da Netflix. CSOnline - Revista Eletrônica de Ciências Sociais, Juiz de Fora, n. 24 (2017) Dez., pp. 1-309.
} 
diversas cenas ao longo da enunciação fílmica, comprovando-nos a hipótese de que o sujeito Travis carrega em si esses traços de personalidade que são envoltos em tristeza, angústia e solidão. Já o processo de reconhecimento entre locutor e interlocutor advém do processo de interação verbal, uma vez que a personalidade que se exprime, segundo Bakhtin e Volochínov (2009), revela-se como produto total da inter-relação social. Como também, há o procedimento pelo qual o sujeito projeta para si uma imagem do seu interlocutor; tal elemento da construção de enunciados é de suma importância, pois é determinante. Sendo assim, as características mais intrínsecas do sujeito são, para nós, evidenciadas por meio de diálogos. Além disso, o modo como o enunciado é construído carrega consigo filiações do sujeito com dado grupos sociais, ou grupos sociais, que são expressos pela escolha das palavras, entonação, entre outros elementos a serem abordados mais à frente. Em vista deste trecho, portanto, podemos conceber fragmentos da personalidade de Travis, analisando todo o contexto de fala que se dá o enunciado.

Assim sendo, elegemos a cena "Travis visits Betsy" para contrastar com a cena posterior, "Travis Supports Palantine" com a finalidade de pormenorizar um, de diversos, posicionamentos enunciativos da personagem protagonista.

Travis, em um certo dia, ao vagar pelas ruas de Nova Iorque em seu táxi, avista de longe, destacada na multidão, uma moça, muito loura, branca e de olhos claros. Ele fala sobre ela em seu diário e a descreve: [Travis narrando enquanto escreve em seu diário] "Eu a vi pela primeira vez na sede eleitoral de Palantine, na 63 com a Broadway. Ela estava usando um vestido branco. Parecia um anjo... no meio dessa imundice. Ela estava sozinha. Eles... não podem... tocá-la." (10min07s a 10min59s).

Travis possui a ideia de que a cidade de Nova Iorque é repleta de "escórias" e se sente extremamente avesso às "imoralidades" que, segundo ele, desencadeiam, portanto, a imagem de Betsy neste momento representando um deus ex machina ${ }^{6}$ para o sujeito. Elementos como o vestido branco de Betsy e traços físicos da atriz bem como sua pele branca, seus olhos claros e seus cabelos louros trazem à tona a possibilidade da analogia a uma entidade divina intocável e impossível de se alcançar, sendo que Travis encontra, ao se deparar com ela, a inspiração de que tanto precisava para sua existência. Além do fato de que esta imagem é a perfeita oposição às "escórias" que tanto atormentam Travis. A partir desse primeiro momento, o taxista começa a ir várias vezes

\footnotetext{
${ }^{6}$ deus ex machina: para a Antiguidade greco-latina, representava um recurso da dramaturgia que consistia na descida em cena de um deus cuja missão era promover uma solução para os personagen. Aqui, nesta cena de Taxi Driver, Betsy representa algo semelhante para Travis, que mergulhado em uma profunda solidão e um caos interno, idealiza nela uma nova inspiração para sua vida.
}

CSOnline - Revista Eletrônica de Ciências Sociais, Juiz de Fora, n. 24 (2017) Dez., pp. 1-309. 
à sede eleitoral apenas para observá-la com a intenção de, posteriormente, conhecê-la pessoalmente $(12 \min 39 \mathrm{~s}$ a $13 \min 39 \mathrm{~s})$.

Primeiramente, é de suma importância que se disserte acerca da imagem que Travis pretende apresentar para Betsy nesse primeiro encontro. $\mathrm{O}$ sujeito Travis costuma usar calças jeans um tanto largas, casacos pesados ou jaquetas jeans em tons mais neutros, como bege e marrom, acompanhadas de uma camisa xadrez. Sua postura, costumeiramente, é desleixada enquanto anda e quando está com seus amigos ou até mesmo só. No entanto, nesta cena do primeiro encontro, Travis está vestindo uma espécie de terno de veludo vinho bem abotoado, justo ao corpo e desta vez, calças de alfaiataria bege, além de seu cabelo estar bem penteado, diferente do habitual. A câmera acompanha a saída de Travis do táxi e à medida que ele caminha até a entrada de sede eleitoral, onde Besty trabalha; seu andar é decidido, enquanto ajeita os pormenores de seu traje.

Assim que adentra o prédio, Travis vai logo em direção à Betsy, apoiando os braços sobre a mesa. E a cena se inicia:

20min33s a 23min23s: [Travis] - Oi. Quero ser voluntário.

[Tom] - Ótimo. Venha comigo.

[Travis] - Prefiro ser voluntário dela, se não se importar.

[Betsy] - Por que tem que ser comigo?

[Travis] - Porque você é a mulher mais linda que eu já vi.

[Betsy] - Obrigada... Mas o que acha de Palantine?

[Travis, um tanto confuso] - Bom, eu...

[Betsy] - Palatine, o cara para quem está querendo ajudar a se eleger presidente.

[Travis] - Tenho certeza de que ele será um bom presidente. Não sei quais são seus planos políticos, mas sei que ele será um bom presidente.

[Betsy] - Quer fazer campanha?

[Travis] - Sim, vou fazer campanha.

[Betsy] - O que acha do apoio do senador à Previdência Social?

[Travis] - Desconheço o programa dele, mas tenho certeza de que é bom.

[Betsy] - Tem certeza?

[Travis] - Sim.

[Betsy] - Trabalhamos todos os dias aqui, dia e noite... pode ir ali, e os senhores irão inscrevê-lo.

[Travis] - A questão é que sou taxista à noite, então, para mim é um pouco difícil trabalhar de dia.

[Betsy] - Então, o que quer exatamente?

[Travis] - Gostaria de tomar um café e comer uma torta comigo?

[Betsy] - Por quê?

[Travis] - Por quê? Eu digo por quê. Acho que você é uma pessoa solitária. Eu passo muito aqui e a vejo. Vejo você cercada de gente... e vejo telefones, a mesa cheia de coisas... que não significam nada. E quando entrei e falei com você... vi nos seus olhos, no seu jeito... que 
você não é feliz. E acho que precisa de alguma coisa. Se quiser chamar de amigo, pode chamar.

[Betsy] - Você vai ser meu amigo?

[Travis] - E então? É um pouco difícil ficar de pé aqui pedindo para você sair, então... Só cinco minutos. Fica aqui do lado. Vou protegêla. Vamos. Só uma pequena pausa.

[Betsy] - Meu intervalo é às $16 \mathrm{~h}$. Se estiver aqui...

[Travis] - Às 16h, hoje?

[Betsy] - Sim.

[Travis] - Estarei aqui.

[Betsy] - Tenho certeza disso.

[Travis] - Certo, às $16 \mathrm{~h}$.

[Betsy] - Certo.

[Travis] - Ah, do lado de fora da porta?

[Betsy] - Sim.

[Travis] - Ah, eu me chamo Travis. Betsy?

[Betsy] - Travis.

[Travis] - Obrigado, Betsy.

Nesta cena, referente à atitude de Travis em relação à Betsy, é possível pontuar características do sujeito e a maneira a qual ele se sente em relação a sua interlocutora, já que ao enunciar, o sujeito tem em seu horizonte a preocupação com seu ouvinte e com o contexto da sua fala. Nesse sentido, entendemos que "cada palavra exala um contexto e os contextos em que leva sua vida socialmente tensa; todas as palavras e formas são povoadas de intenções" (VOLOCHÍNOV, 2013, p. 69).

Travis, logo no início do diálogo, expressa seu desejo em tornar-se voluntário da campanha e ao recusar ser atendido por Tom (Albert Brooks) já deixa claro o seu interesse por Betsy. No entanto, quando ela pergunta sobre o que Travis pensa sobre o candidato, Travis parece desconcertado e confuso, como se não soubesse a quem ela havia se referido. De fato, Travis não o conhece e tampouco está a par do plano de governo do candidato. Ao reconhecer que não têm entendimento sobre o candidato e sobre o seu projeto de campanha, o sujeito denuncia seu descaso com determinados assuntos sociais, políticos, econômicos e ideológicos, confirmando, assim, uma característica importante de seu discurso direcionado às minorias marginalizadas em uma cena anterior $(5 \min 54 \mathrm{~s}$ a $6 \min 47 \mathrm{~s})$. Nesse sentido, ao opinar sobre um assunto social se faz necessário debruçar sobre o tema, de modo a aprofundar seu contexto, antes de se posicionar em relação a ele. Quando Travis enuncia um discurso de ódio dirigido a essa fração da sociedade novaiorquina isto é feito de maneira não embasada, sendo apenas uma opinião sem conhecimento das causas que mantém essa estrutura social pobre, miserável e fragilizada. Ao estabelecer um juízo de valor negativo sobre a sociedade em que vive, o sujeito Travis assume uma responsabilidade sobre sua CSOnline - Revista Eletrônica de Ciências Sociais, Juiz de Fora, n. 24 (2017) Dez., pp. 1-309. 
avaliação, uma vez que, conforme Bakhtin, "O falante é um homem essencialmente social, historicamente concreto e definido, e seu discurso é uma linguagem social [...]" (BAKHTIN, 2015, p. 124; grifos do autor). Consequentemente, ao renunciar um conhecimento mais aguçado a fim de satisfazer suas reflexões sobre a sociedade, ele se torna um sujeito alienado e desvencilhado da realidade, sendo seu discurso desamparado de um conhecimento concreto não correspondente à realidade em suas diversas faces.

Além disso, Travis, mesmo demonstrando não saber nada a respeito de política, afirma que sabe o que é um bom plano governamental e que Charles Palantine é um bom candidato. Vê-se mais uma vez que Travis faz afirmações a respeito de algo que não detém entendimento, na busca por aproximar-se de Betsy.

Logo após essas investidas mal sucedidas, Travis revela para Betsy o real motivo de estar ali e ela o questiona sobre seu interesse em sair com ela. A resposta de Travis soa como um discurso existencialista e anti materialista quando observa uma espécie de solidão em Betsy e quando questiona o valor material dos objetos que a cerca e das pessoas com quem ela trabalha. Ao fazer tais observações, Travis afirma que Betsy precisa de um amigo, pois segundo ele, lhe falta algo de verdadeiramente significativo. Concluindo, ele encontra alguém que está em uma mesma situação em que ele está. Configura-se aí uma relação de identificação de Travis para Betsy, em que, a partir das perspectivas do eu-para-mim e do outro-para-mim (BAKHTIN, 1997, p. 44), o taxista concebe sua interlocutora como sendo a projeção do ideal de sua realidade ou algo que ele almeja como o ideal. Betsy representa para Travis a "pureza" que caminha por entre a "imundice". Através das relações entre a projeção do interlocutor (Betsy) que o enunciador (Travis) faz e da ideia que esse enunciador faz de si mesmo é que se propiciou essa identificação por parte de Travis.

Esta resposta de Travis não condiz com o sujeito que qualificamos anteriormente como alienado e ignorante pela complexidade e profundidade do seu dito que mais se aproxima de uma premissa filosófica da existência do indivíduo em relação à vida em sociedade. Betsy, por outro lado, parece ter sido convencida por estas últimas palavras de Travis e, ao que parece, ter correspondido de fato à maneira como ela se sente. Betsy não demonstra nenhuma resistência às investidas de Travis. Sendo assim, o diálogo se finda com o convite aceito por Betsy e, em seguida, inicia-se assim, a segunda parte da cena:

$23 \min 44 \mathrm{~s}$ a $27 \min 29 \mathrm{~s}$ : [Travis narrando] - 26 de maio, 16h. Levei CSOnline - Revista Eletrônica de Ciências Sociais, Juiz de Fora, n. 24 (2017) Dez., pp. 1-309. 
Betsy para tomar um café no Charle's Café. Pedi café preto, torta de maçã e um pedaço de queijo amarelo derretido. Acho que foi uma boa escolha. Betsy pediu café e salada de fruta. Ela podia pedir o que quisesse.

[Betsy] - Quinze mil voluntários só em Nova York não é nada mal. Mas é difícil organizar.

[Travis] - Sei muito bem. Tenho o mesmo problema. Tenho que me organizar. As pequenas coisas, como minha casa, minhas coisas. Preciso arrumar uma placa que diz: "Um dia desses vou me organizizar".

[Betsy] - Quer dizer, 'organizar'?

[Travis] - Organizizar. Organizizar. É uma piada.

[Betsy] - Ah... 'Organizizar'. Eu também vi um parecido com essa.

[Travis] - Gosta de onde trabalha?

[Betsy] - Temos boas pessoas. Acho que Palantine tem uma boa chance.

[Travis] - Sabia que seus olhos são lindos? Gosta do cara com quem trabalha?

[Betsy] - Ele é legal.

[Travis] - Sei, mas você gosta dele?

[Betsy] -Ele é engraçado e é bom no que faz. Ele é legal. Mas ele tem uns problemas.

[Travis] - Eu diria muitos. Ele parece desperdiçar energia nos lugares errados. Quando entrei e vi vocês sentados lá... dava pra ver que não havia conexão nenhuma. E eu senti que quando eu entrei, havia alguma coisa entre nós. Um impulso que nós dois estamos seguindo. $\mathrm{E}$ isso me deu o direito de falar com você. Caso contrário, eu nunca sentiria que tinha o direito de falar com você. Nunca teria tido coragem de falar com você. E com ele, senti que não havia nada. Quando entrei, vi que eu tinha razão. Você também sentiu isso?

[Betsy] - Eu não estaria aqui se não tivesse sentido.

[Travis] - Você é de onde?

[Betsy] - Do norte do estado.

[Travis] - Não gosto daquele cara. Não que eu não goste, só acho ele babaca. Acho que ele não respeita você.

[Betsy] - Acho que nunca conheci alguém como você.

[Travis] - Quer ir ao cinema comigo?

[Betsy] - Preciso voltar ao trabalho agora.

[Travis] - Não agora. Uma outra hora?

[Betsy] - Claro. Sabe o que você me lembra? Aquela música... do

Kris Kristofferson. "Ele é um profeta e um traficante, meio verdade, meio ficção; uma contradição".

[Travis] - Está falando de mim?

[Betsy] - De quem mais podia ser?

[Travis] - Não sou traficante. Nunca trafiquei.

[Betsy] - Não, só a parte que fala em contradições. Você é isso.

Neste segundo diálogo entre Travis e Betsy é possível pôr em xeque novamente o perfil contraditório do sujeito. Não nos atentaremos às falas correspondentes às tentativas de Travis de manter o diálogo, mas sim, aos enunciados mais decisivos que começam a partir do momento em que ele inicia seu julgamento sobre o colega de Betsy, Tom. O modo que Travis fala acerca de Tom é tão preciso e 
seguro que temos a impressão de estar ouvindo alguém que o conhece intimamente. Em alguns momentos, o espectador se confunde, pois o sujeito enuncia em um tom hábil ao analisar pessoas e essa confusão se dá porque em alguns momentos essa habilidade parece não existir para com outros elementos da vida. Um exemplo disto está presente nesta cena, como veremos a seguir.

Betsy está visivelmente deslumbrada com a capacidade de Travis em observar, tanto ela quanto seu colega e, após isso, ele esclarece o que motivou a ter ido conhecêla. Temos aí a confirmação de que ele, ao menos se identificou com ela, não apenas pela solidão de que ambos compartilham, mas porque ao considerar os outros como "escória", obviamente ele não se considera como integrante disso, portanto, ele é algo oposto ao termo que ele costuma usar. Como ele não a considera parte da escória também, logo, eles tem muito que compartilhar como, por exemplo, o "impulso que ambos estão seguindo", segundo Travis.

Partindo para o outro enunciado decisivo, nos atentamos para o momento em que Betsy, ao se lembrar de uma canção, aponta uma semelhança entre a letra da música e a personalidade de Travis: [Betsy] "Claro. Sabe o que você me lembra? Aquela música... do Kris Kristofferson. 'Ele é um profeta e um traficante, meio verdade, meio ficção; uma contradição'.” (26min29 s 27min00s). Espantosamente e contrariando suas atitudes analíticas anteriores, Travis não compreende o enunciado de Betsy que é uma mensagem composta de antíteses resultando numa enunciação que contém complexidade. Travis afirma "não ser traficante", ou seja, Travis se ateve apenas para o caráter mais prático da letra da canção, confirmando a ideia proferida nesta pesquisa e a declaração de Betsy: Travis é, sobretudo, um sujeito contraditório.

No entanto, a contradição do sujeito Travis não lhe é exclusiva. A contradição é um dos vários elementos presentes na constituição do sujeito na vida, já que sendo “[...] o processo de formação ideológica do homem, um processo de assimilação seletiva das palavras dos outros." (BAKHTIN, VOLOCHÍNOV, 2013, p. 135). Ou seja, o sujeito está sempre à mercê de diversos discursos alheios que lhe são constantemente transpassados. Logo, na enunciação fílmica em estudo, conseguimos observar múltiplos discursos, inclusive contraditórios, que participam da constituição e da ininterrupta transformação do sujeito como, por exemplo, o discurso conservador da ultra direita que persiste na ideia da "higienização social"7 sem considerar as causas da miséria e da

\footnotetext{
${ }^{7}$ Esta ideia de higienização social proferida pelo discurso conservador de ultra direita equivoca-se ao considerá-la como solução definitiva e moral aos problemas sociais ao ignorar as causas que levaram a CSOnline - Revista Eletrônica de Ciências Sociais, Juiz de Fora, n. 24 (2017) Dez., pp. 1-309.
} 
marginalidade, de modo a combatê-la com ações e projetos sociais voltados para a cidadania e o discurso filosófico-existencialista de Sartre com a sua tese sobre a liberdade encontrar-se associada à solidão.

A tese filosófica sartreana prega, especialmente em A Náusea (1938) que, através do reconhecimento pelo sujeito da sua liberdade é impossível desassociá-la da solidão, ou um sentimento de natureza semelhante, como uma espécie de "náusea", segundo o eu-lírico desse romance de Sartre. Esse sentimento se dá pela revelação que o sujeito tem de que a liberdade é estar só e desvencilhado do mundo pela indiferença desencadeada. Caracteriza-se aí uma espécie de ateísmo, também, ao ignorar noções metafísicas. No entanto, o que nos interessa para pensar a arquitetônica fílmica de Taxi Driver é a semelhança entre estes discursos proferidos pelo sujeito Travis (não apenas na cena analisada como também em muitas outras, o que demonstra a recorrência desse dizer) e o discurso filosófico-existencialista de Sartre: “Quando se vive, se sucede nada. Os cenários mudam, as pessoas entram e saem; é tudo. Nunca há princípios. Os dias sucedem os dias, sem tom nem som, é um alinhamento interminável e monótono." (SARTRE, 2011, p. 60). Este trecho dialoga com uma cena em que Travis escreve em seu diário:

53min16s a 53min55s [Travis] A solidão sempre esteve ao meu lado a vida toda, em todo lugar. Nos bares, nos carros, nas calçadas, nas lojas, em todo lugar. Não há saída. Sou um homem sozinho de Deus. Oito de junho. Minha vida mudou de rumo outra vez. Os dias passam, todos iguais... um dia igual ao outro... como uma cadeia longa e contínua.

Travis é um sujeito solitário que mediante a sua compreensão da solidão, fruto de sua desesperança e niilismo, que passa a buscar um sentido para a sua existência e reflete sobre ela de maneira semelhante a um filósofo nato. E é a partir desse acontecimento que o contrapomos aos discursos marcados pela hostilidade, aqueles para com as minorias marginalizadas e as reflexões que ele faz sobre o modo de vida desses grupos, que, segundo Travis, eles são a "escória". Atentamos ao fato de que o taxista possui uma habilidade genuína em refletir sua existência, mas peca ao enunciar um discurso alienado sobre sua sociedade. Eis aí uma de suas contradições.

Portanto, esta cena de Taxi Driver nos apresenta características relevantes sobre Travis, uma vez que consiste num diálogo. A complexidade é inerente à análise

este produto e, ainda, pelo caráter violento que traz consigo, pois, a maneira de concretizar a higienização seria por meio de mortes dessa população em estado de miséria e dos usuários de drogas.

CSOnline - Revista Eletrônica de Ciências Sociais, Juiz de Fora, n. 24 (2017) Dez., pp. 1-309. 
produzida pois, consideramos todo o contexto envolto neste evento, tais como, a quem Travis se dirige, o que ele diz e como diz. Além das características que nos são disponíveis por se tratar de um filme, tais quais a postura de Travis, a aparência de sua interlocutora, as expressões, entre outros. Todos esses elementos significam na arquitetônica fílmica em prol do todo enunciativo e qualificam o sujeito em estudo ao mesmo tempo que acompanhamos sua transformação e suas diversas maneiras de agir perante um interlocutor diferente, como veremos a seguir.

\section{As marcas ideológicas nos posicionamentos do sujeito Travis}

$\mathrm{Na}$ cena intitulada por nós de "Travis Supports Palantine" (28min23s a 30min48s) o sujeito protagonista Travis Bickle recebe um passageiro incomum em seu táxi, o candidato à presidência dos EUA, o senador Charles Palantine (Leonard Harris). Eles iniciam um rápido diálogo em que se pode descobrir mais sobre o posicionamento ideológico do sujeito Travis como também do sujeito candidato. Sendo este posicionamento exposto por Travis, nessa cena específica, um fragmento dos elementos que destacamos para analisar o sujeito, tanto suas motivações e movimentações quanto a sua transformação. E esses elementos são traços constituintes do sujeito que ecoam nas suas palavras e ações, pois, neste diálogo, Travis materializa, por meio dos enunciados, a sua visão de mundo quando se posiciona para com o outro e para consigo mesmo, assim como afirma Bakhtin (2015, p. 127): “A ação do herói romanesco ${ }^{8}$ sempre é ideologicamente destacada: ele vive e age em seu próprio universo ideológico [...], tem sua própria apreensão do mundo, que se materializa na ação e na palavra."

Ao se expressar, Travis se revela e não o faz sozinho, denuncia também a(s) $\operatorname{voz}($ es) do(s) seu(s) grupo(s) social(is). Já a singularidade dessa cena encontra-se na maneira em que são expressas as ideias e ideais dos interlocutores, uma vez que são proferidas de uma forma peculiar em relação a outros momentos da narrativa fílmica os quais Travis se referira ao mesmo tema do diálogo com Palantine, anteriores e posteriores. Um exemplo é uma das cenas iniciais do filme em que o taxista, em um tom de prece e de aversão, beirando a um discurso de ódio, "anseia por uma 'chuva' que seja capaz de remover toda a escória das ruas de Nova Iorque, todo o 'lixo' que fica nas calçadas da cidade à noite" (5min54s a 6min47s). Logo adiante, "a escória" a qual ele se

\footnotetext{
${ }^{8}$ Mesmo que os escritos de Bakhtin tenham sido sobre o herói na e da literatura, entendemos a produtividade de seu pensamento para o estudo de outras linguagens, além da literária, como o cinema, por exemplo, aqui retratado na análise da enunciação fílmica a partir do diálogo.

CSOnline - Revista Eletrônica de Ciências Sociais, Juiz de Fora, n. 24 (2017) Dez., pp. 1-309.
} 
refere será fragmentada e explicitada por Travis e, assim, será possível visualizar melhor este seu posicionamento, por conseguinte, os efeitos de sentidos desses enunciados para o diálogo travado.

A análise desta cena será diferente da anterior; aqui, fragmentamos as falas, visto que esta cena está repleta de enunciados um tanto quanto obscurecidos pelo processo metafórico produzido, caracterizando, assim, uma cena complexa.

O diálogo, antes de ser iniciado, conta com uma conversa em tom de discrição entre o candidato e um de seus dois guardas. Esse tom é caracterizado pelas vozes que não se sobressaem, pois o assunto apresenta-se sigiloso. No entanto, elas estão presentes e têm sua importância para a construção da narrativa fílmica.

28min23s a 28min40s: [Guarda1, em voz baixa] - Não precisa se preocupar se alguém está se comprometendo até as coisas começarem a chegar da Califórnia. Ouça, isto está me deixando nervoso, devíamos ter esperado a limusine.

[Senador Palantine]: Não me importo em pegar táxi, mas me importo em ir à Califórnia sem estar preparado. Isso vai nos trazer problemas.

Ora, neste momento eles se referem ao modo de vida da cidade (Califórnia) que, àquela época ${ }^{9}$, pelos mais conservadores, compreendia essa característica de ser "para frente", como fora citado por um dos colegas de trabalho de Travis, em uma das cenas mais adiante, sobre os direitos dos homossexuais que lá existem, e eles têm notoriedade, (44min45s a 45min24s). Ao contrário de Nova Iorque que ainda está presa à moral repleta de preconceitos. Sendo assim, um candidato republicano, como no caso de Palantine, pode ter alguma desvantagem ao visitar a cidade sem estar preparado para um discurso que não irá ferir esta parcela da sociedade e ainda agradar aos que são simpatizantes da sua campanha.

A cena, por completo, possui em primeiro plano o discurso político e este discurso encontra-se repleto ecos, ressonâncias, silêncios e presumidos entre os interlocutores, sendo que "na vida, o discurso verbal é claramente não auto suficiente." (BAKHTIN, VOLOCHÍNOV, 1976, p. 4) e que "toda estrutura formal da fala depende, em grau significativo, de qual é a relação do enunciado com o conjunto de valores presumido do meio social onde ocorre o discurso.” (BAKHTIN, VOLOCHÍNOV, 1976, p. 8). Ou seja, além de estarem atento à enunciação concreta, os participantes do diálogo

\footnotetext{
${ }^{9}$ Uma das hipóteses da nossa pesquisa, refere-se à contextualização histórica do acontecimento da narrativa fílmica. Com bases em pistas sobre a biografia do sujeito protagonista (contidas na obra), Travis Bickle, dentre outros aspectos semelhantes à realidade época, tomamos a ideia de se que refere à mesma época em que o filme foi produzido/exibido, ou seja, década de 1970, no século XX.
}

CSOnline - Revista Eletrônica de Ciências Sociais, Juiz de Fora, n. 24 (2017) Dez., pp. 1-309. 
precisam estar familiarizados com o ambiente situacional, que no caso é uma disputa política; e também, atento às expressões do corpo, entonação do enunciado e quaisquer elementos que não estejam comportados unicamente à fala e para além da fala. $\mathrm{O}$ candidato, na maioria das vezes, faz o máximo para adquirir mais simpatizantes, recorrendo a modos de fala que camuflam sua real posição, isso em discursos com um público de maior dificuldade de identificação, ou até mesmo discursos demagogos. $\mathrm{O}$ discurso político tenta sempre se ajustar às mais diversas possibilidades de público, contexto histórico, social e ideológico. E nota-se essa habilidade no diálogo entre Palantine e Travis.

Logo após esse comentário a respeito da Califórnia, Travis reconhece Palantine e, em seguida, demonstra seu entusiasmo e um suposto fanatismo pelo candidato. $\mathrm{O}$ taxista manifesta-se como sendo adepto às propostas do senador (o que não representa a realidade de Travis, pois ele não está a par do plano de governo de Palantine) e diz que gostaria de fazer propaganda com adesivos, mas que era impedido disso, já que a empresa o proibiu de realizar tais manifestações eleitorais. Travis se refere às pessoas da empresa como "uma turma de imbecis" por não apoiarem este candidato ou se posicionarem neutros em relação à disputa política. Em seguida, Palantine se esquiva deste assunto com um comentário acerca de que ele tem "aprendido mais sobre os EUA andando de táxi do que de limusine", a fim de reafirmar seu personagem político.

\footnotetext{
28min42s a 29min00s: [Travis empolgado] - Você é Charles Palantine, o candidato?

[Senador Palantine]: Sim, eu sou.

[Travis] - Sou um grande partidário. Digo a todos que entram nesse táxi para votar no senhor.

[Senador Palantine] - Nossa, obrigado... Travis.

[Travis] - Tenho certeza de que vai ganhar Todos que conheço vão votar no senhor. Eu ia colocar um adesivo seu no meu táxi, mas a empresa disse que não era permitido. Mas eles não deixam nada. É uma turma de imbecis.

[Senador Palantine] - Vou te dizer uma coisa, tenho aprendido mais sobre os EUA andando de táxi do que de limusines.
}

Agora, retomando a fala de Palantine sobre andar de táxi e o que ele aprendeu deixando de andar de limusine, entende-se que ele se debruça ao povo para uma imagem de líder que vai governar com as massas, e passou a ter mais entendimento de seus anseios andando num veículo regular do cotidiano do que ostentando em um carro luxuoso e, certamente, mais seguro, por ser particular. Uma atitude que também contribui para estabelecer uma imagem de homem humilde. 
Mudando o foco de Palantine para Travis, é interessante notar as divergências entre o conteúdo de sua fala e a realidade já exposta (e a que ainda virá a tona ao longo do filme). Primeiramente, o taxista diz, entusiasmado que é "um grande partidário" sendo que, o interesse de Travis em Palantine, primeiramente é outro, indireto, ou seja, um meio para o fim, como demonstrado na cena anterior, "Travis visits Betsy". O taxista não demonstra interesse e conhecimento sobre a política nacional e nem em que é candidato ao cargo, portanto, ele não é o que diz ser. Além disso, ao sugerir que ele diz aos seus passageiros que votem no candidato, Travis esconde a sua verdade de que nem ao menos ele tenta conversar com seus passageiros. Em várias cenas em que vemos Travis levando pessoas em seu táxi, ele demonstra indiferença e não tenta estabelecer nenhum vínculo amigável; sua expressão é sempre desgostosa, diferente da empolgação com a qual ele se dirige ao senador. Em segundo, Travis diz que tentou fazer propaganda da campanha de Palantine e que não foi permitido, culpabilizando a empresa responsável pelo serviço de táxi pela impedimento da ação. No entanto, podese refletir que, muito provavelmente esta prática seja ilegal e não apenas um veto específico dessa empresa. Salientamos, ainda, que a verdadeira situação é a em que Travis nunca ter havido demonstrado um interesse real em fazer campanha política, pois, seu objetivo era apenas se aproximar de Betsy; no entanto, esse objetivo é atravessado pela campanha eleitoral. Em vista disso, ao não ser sincero à sua realidade, notamos os traços de contradição do sujeito.

A partir daí, Palantine pergunta a Travis se ele pode lhe fazer uma pergunta, entusiasmado, ele responde "sim". A pergunta do candidato é: "Que coisa mais o incomoda no país?". Travis começa a denunciar a si mesmo, ao dizer que não sabe muito sobre política. Palantine sugere que ele diga o que mais lhe incomoda, pois, de acordo com ele,deve haver algo.

29min10s a 30min08s: [Senador Palantine] - Posso fazer uma pergunta, Travis?

[Travis] - Claro.

[Senador Palantine] - Que coisa no país mais incomoda você?

[Travis] - Bem, eu não acompanho muito de perto essas questões políticas, senhor.

[Senador Palantine] - Ah, deve haver alguma coisa.

[Travis] -Bem, o que quer que seja, deviam limpar essa cidade porque essa cidade é tipo um esgoto a céu aberto. Cheio de imundície e escórias. Às vezes, não aguento. Quem for presidente deve limpá-la de verdade. Entende? Às vezes, eu saio e sinto o cheiro e me dá dor de cabeça. É horrível. E ela nunca passa. Acho que o presidente devia limpar essa bagunça toda. Devia puxar a descarga dessa maldita 
privada.

Neste momento, a fala de Travis soa como um discurso autoritário e altamente preconceituoso. A "sujeira" à qual ele se refere são as chamadas minorias, como dito por ele logo no início do filme: as prostitutas, os negros, os homossexuais, drag queens, maconheiros e viciados, os corruptos, que de uma forma generalizante ele denomina de "escória" (5min54s a 6min47s). E a "limpeza" a qual ele se refere, certamente é a eliminação dessa "sujeira" (das minorias que vivem marginalizadas socialmente) que o incomoda tanto a ponto de lhe causar náuseas e dor de cabeça. Importante destacar que nesse enunciado é metaforizado, ou seja, ele não é claro quanto ao efeito de sentido das expressões que usa, como "sujeita", "escória" e "limpeza", que nesta fala de Travis não equivalem ao seu sentido denotativo.

Bem como o conteúdo de seu enunciado, podemos nos atentar para com as expressões corporais e faciais, além da entonação, já que uma obra cinematográfica nos permite visualizar e pormenorizar esses elementos. A face de Travis neste momento perde o semblante entusiasmado e seu rosto torna-se sombrio com nuances de repugnância; ele vocifera com ódio e revolta, como se seu discurso se dirigisse diretamente a "seus inimigos". Ele perde a concentração no volante e ouve-se uma buzina; ele perdeu, por alguns segundos, a atenção no trânsito. Ao término de sua fala um silêncio se estende, beirando a um leve constrangimento, logo, notamos que está desnorteado. Por isso, a análise do enunciado de Travis, se volta, também, para a sua gesticulação, entonações usadas, etc. já que contribuem para a produção de sentidos ao revelar para nós o sujeito que enuncia; isso, de acordo com Voloshinov (1976, p. 9):

[...] a entonação e o gesto são ativos e objetivos por tendência. Eles não apenas expressam o estado mental passivo do falante, mas também sempre se impregnam de uma relação forte e viva com o mundo externo e com o meio social - inimigos, amigos, aliados. Quando uma pessoa entoa e gesticula, ela assume uma posição social ativa com respeito a certos valores específicos e esta posição é condicionada pelas próprias bases de sua existência social.

Ou seja, além da análise dos enunciados, precisamos levar em conta, também, o seu material extra-verbal, pois como visto, a entonação e o gesto não apenas correspondem à ação psicofísica, mas, além disso, estabelecem uma associação concreta com o seu(s) contexto(s) de surgimento enunciado, sua realidade concreta. Travis, quando perde o controle do volante ou, quando vocifera, se posiciona e reafirma seus valores e ideais ao reagir de maneira colérica, como se seu discurso fosse direcionado 
especificamente ao público que ele busca atingir.

Este pensamento de Travis pode ser entendido como uma das ideologia mais marcante da década de 1970 nos EUA, uma época, em especial para este filme, em que ainda havia Guerra do Vietnã (1955-1975), que mexeu com a população norteamericana, que por um lado eram feitos pedidos de paz e, na outra parcela, houve a intensificação do orgulho estadunidense, pois a Guerra do Vietnã se enquadra no contexto de Guerra Fria.

É uma forma de pensamento tipicamente conservadora, que deposita em algum ou vários grupos populacionais, a culpa da decadência no país, nas doenças, criminalidade, economia, e outros setores. Aliada a essa ideologia, está o sujeito Travis, ex-fuzileiro naval, dispensado com honra, jovem, com cerca de 26 anos, extremamente solitário, sofre de insônia e assiste ao caos que a cidade de Nova Iorque é na década de 1970 (2min30s a 4min14s). Sem objetivos de vida, perambula pelas ruas da metrópole e, depois de uma desilusão amorosa (33min10s a 36min53s) com Betsy, pretende buscar um sentido para sua vida. Não aleatoriamente, o sentido que ele lhe impõe é tentar limpar com suas próprias mãos, a sujeira da sua cidade. Uma atitude que, segundo os ideais de Travis, é "patriótica", uma vez que, tendo ele sido do exército, e, havendo portanto, um discurso de ex-soldado, há uma aproximação de uma ideia de proteger a sua nação de um suposto inimigo, ou seja, um inimigo que de acordo com o taxista são as minorias marginalizadas. O que, consequentemente, se linha ao anseio de Travis pela "chuva de verdade, que limpará todo o lixo das ruas". Sem que isso seja, em sua visão, um ato de heroísmo, mas sim, um dever. No entanto, podemos problematizar esses princípios de Travis em que, ao se posicionar desta maneira está refletindo sua indignação e, portanto, uma solução que ele considera a correta para o desaparecimento do problema. Sabemos ainda, que, esta solução está associada à ideologia ultraconservadora em que, normalmente, se aponta para ao problema a fim de erradicá-lo, ao invés de explorar a causa para entender de fato o todo da problemática.

Assim, um dos elementos que constituem esse discurso de Travis é o fato de que, sendo ele um ex-soldado, ou seja, tendo ele sido membro de um grupo social organizado com fins de eliminação do inimigo, ou seja, uma guerra, isso lhe possibilita ter essa opinião acerca da situação de Nova Iorque; ou seja, esta ideia representa a voz do grupo social o qual Travis, um dia, esteve inserido.

A entonação com a qual é dita este enunciado de Travis, faz transbordar toda a sua raiva para com a "escória", o que assusta em um primeiro momento um dos guardaCSOnline - Revista Eletrônica de Ciências Sociais, Juiz de Fora, n. 24 (2017) Dez., pp. 1-309. 
costas e, de certa forma, o próprio candidato, uma vez que o vocabulário de Travis é bruto e repleto de palavras que chocam (pela escolha da metáfora para se referir às minorias "escória", "lixo"), e que, portanto, lhes causaram um visível desconforto e espanto. Ou seja, a escolha lexical feita por Travis para se expor lhe são convenientes, uma vez que refletem sua identidade, seu grupo social, seus ideais. Já para o guarda e para Palantine não correspondem diretamente ao mesmo horizonte de significação, pois eles certamente se referiram de outra maneira em um discurso semelhante ao de Travis, pois ambos possuem outro lugar social de fala; isto é, este é um lugar mais privilegiado (em níveis de hierarquia social) em relação ao de Travis. No entanto, o local de fala de Palantine e dos seus guardas também diferem entre si, pois o senador se encontra no âmbito da política e é uma pessoa pública, enquanto que seus guardas, por serem seu funcionário, o acompanham. Muito embora isso não atrapalhe o entendimento da fala de Travis, eles compreendem a mensagem quase que codificada do taxista e em seguida, Palantine concorda com Travis.

30min12s a 30min22s: [Senador Palantine] - Bem, eu acho que sei o que quer dizer, Travis. Mas não vai ser fácil. É preciso fazer mudanças radicais.

[Travis] - Tem razão.

Como resposta, temos uma expressão que também aparece amenizada ou outra mensagem quase codificada, pois, o que seriam essas mudanças radicais? Talvez segregação, a imposição do preconceito, diminuição dos direitos, uma "caça às bruxas" ou até mesmo extermínio? Isso não fica claro na resposta de Palantine, mas sabendo de sua posição ideológica conservadora, pressupõe-se algo dessa natureza. E, mais uma vez, mesmo não explicitando o caráter de tais medidas radicais, Travis compreende e concorda com a resposta do Senador Palantine, demonstrando o seu descontentamento já que ambos partilham de semelhante juízo de valor.

O diálogo finda-se aí quando eles chegam ao destino do candidato. $\mathrm{Na}$ despedida, eles se cumprimentam amigavelmente e há uma fala interessante de Travis a Palantine.

30min30s a 30min45s: [Senador Palantine] - Foi um prazer conversar com você.

[Travis] - Foi um prazer conversar com o senhor. O senhor é um homem de bem. Eu sei que vai ganhar.

[Senador Palantine] - Obrigado. Dirija com cuidado.

Há nesse enunciado uma confirmação, que podemos denominar de mais CSOnline - Revista Eletrônica de Ciências Sociais, Juiz de Fora, n. 24 (2017) Dez., pp. 1-309. 
evidente em relação às anteriores, que são um tanto obscurecidas pela processo metafórico, da identificação entre interlocutores. Travis se refere a Palantine como um "homem de bem". Ora, isso porque na concepção de Travis, ao concordar com a sua opinião sobre a "limpeza da escória", Palantine representa seu ideal estando de acordo em “fazer o 'bem' para os verdadeiros cidadãos dos EUA". Por isso, “homem de bem”. Outra parte desse enunciado que chama a atenção é que a confiança que Travis tem acerca da vitória de Palantine é de que o senador representa a maioria da população, o que de certa forma, pode ser verdade, pois corresponde ao estereótipo estadunidense que é explorado na narrativa fílmica e que possui suas marcas verídicas na história. Como dito por Lubin $(2005$, p. 35) “[...] o filme é um documento histórico sobre a pressão intensa para com a crise urbana Americana" ${ }^{10}$.

Portanto, os posicionamentos de Travis frente à uma população de situação frágil mostra que eles se tornam o inimigo em potencial dos Estados Unidos. Sendo a década de 1970 sendo marcada pela desesperança no governo, na vida de um modo geral, o crescimento do narcisismo e individualização, fazendo com que esta década fosse considerada como década "Me" (1976). Que, segundo Tom Wolfe, o criador do termo, se referia à obsessão na gratificação pelos próprios atos e por materialidades; consequência dos sentimentos de desilusão que a época concebeu. Travis funciona como o representante máximo dessa problemática, e, confirmamos essa hipótese pela análise dos enunciados, por ele, produzidos.

\section{Considerações finais}

O taxista Travis Bickle é uma personagem demasiadamente famosa no universo cinematográfico, tanto pelo prestígio do diretor, Martin Scorsese, quanto por configurar a representação de um homem estadunidense comum, mas que, ao cometer um feito de alta gravidade por ordem de suas posições ideológicas, nos faz refletir sobre o modo de vida pós-contemporâneo ocidental. Além de acompanharmos a vida de um taxista solitário, ardente pela busca do seu ideal de mundo melhor, a narrativa fílmica nos obriga a repensar tanto os discursos em circulação na sociedade como também os que o motivaram em Taxi Driver. Pensar este filme nos faz pensar a vida e, como sendo um produto social, possui reflexos e refrações das ações dos sujeitos, através da ação

\footnotetext{
${ }^{10}$ Tradução nossa. No original, em inglês: "[...] the film is a historical document about the boiling pressure from America's urban crisis."

CSOnline - Revista Eletrônica de Ciências Sociais, Juiz de Fora, n. 24 (2017) Dez., pp. 1-309.
} 
dialógica de interação verbal entre interlocutores.

Sendo assim, neste trabalho, conseguimos perceber a complexidade que a enunciação fílmica possui através das ações de Travis Bickle juntamente com os enunciados por ele produzidos que expressam contrariedade constante pela luta ideológica presentes no sujeito. Ao mesmo tempo que as marcas desses discursos distintos e, por vezes opostos, podem ser fragmentadas para melhor visualização, não podemos nos esquecer de que elas moldam o sujeito, ou seja, coexistem no todo. Configura-se aí o ato complexo, pois ao pensar, agir e ser, o fazemos em sua totalidade.

Portanto, concluímos que a construção da enunciação fílmica e seus efeitos de sentido se dão a partir dos diálogos travados pelo sujeito Travis Bickle com os "outros" que circundam, a variedade de discursos que o corroboram advindos do meio social e em um determinado período da história, com a finalidade de pensar sobre o conflito gerado pelos participantes da enunciação fílmica na formação do sujeito Travis. A partir disso:

[...] suponhamos inclusive que uma pessoa esteja irritada com a sociedade; ainda assim, quanto mais irreconciliável for sua hostilidade contra ela, quanto mais pretenda afirmar o próprio "eu" individual, o próprio 'arbítrio' - como disse uma personagem de Dostoiévski - tanto mais clara será a forma dialógica de seu discurso interno, tanto mais claramente se observará o conflito num único fluxo verbal de duas ideologias, de duas visões de classe que lutam entre si. (BAKHTIN, 2015, p. 166)

E é justamente esse o fluxo, ou melhor, essa movimentação dialógica, que pode ser visualizada nesta pesquisa: um fluxo dialógico que ao mesmo tempo que constitui o sujeito também o revelou para nós. Estas duas cenas da enunciação fílmica, "Travis visits Betsy" e "Travis supports Palantine" nos mostram dois sujeitos diferentes: de um lado, um que trata uma moça com cordialidade e se mostra um rapaz dotado de habilidades analíticas, reflexões filosóficas e, de outro, um sujeito que ecoa um discurso de ódio para com grupos marginalizados de Nova Iorque. Essas cenas de Travis são conflituosas e trazem ao cerne da questão a reflexão sobre o sujeito na vida, partindo da perspectiva do sujeito na arte. Devido a isso, podemos supor que, Tavis é, "esse sujeito que (re)constrói a cidade enquanto texto e se inscreve nele, engrenando, em meio a este amontoado de signos da superfície da folha pergaminho, um traçado de uma possível legibilidade." (GOMES, p.39). A narrativa fílmica apresenta para nós uma crônica urbana contada ora pelos olhos de Travis ora pelas janelas do seu táxi; a cidade por ele é 
lida de acordo com diversos vieses, cada qual revela para nós os elementos constituintes do nosso vilão/herói.

\section{Referencial teórico:}

BAKHTIN, Mikhail. Teoria do romance I: A estilística do romance / Mikhail Bakhtin; tradução, prefácio, notas e glossário de Paulo Bezerra; organização da edição russa de Serguei Botcharov e Vadim Kójinov. São Paulo: Editora 34, 2015. BAKHTIN, M. M./VOLOCHÍNOV, V. N. (1929). Marxismo e Filosofia da Linguagem. Trad. Michel Lahud e Yara Frateschi Vieira. 13 ${ }^{\mathrm{a}}$ ed., São Paulo: Hucitec, 2009.

BAKHTIN, M. M. Estética da criação verbal. Trad. Maria Ermantina Galvão G. Pereira. São Paulo: Martins Fontes, 1997. 2010 . Para uma filosofia do ato responsável. São Carlos: Pedro e João Editores,

GOMES, Renato Cordeiro. Todas as cidades, a cidade: literatura e experiência urbana / Renato Cordeiro Gomes; prefácio de Eneida Maria de Souza. - Ed. ampl. - Rio de Janeiro: Rocco, 2008.

HALL, Stuart. A identidade cultural na pós-modernidade. Trad. Tomaz Tadeu da Silva \& Guacira Lopes Louro. Rio de Janeiro: Lamparina, 2015.

LUBIN, Joshua Elliot. American Disillusionment and the search for self-fulfillment in the 1970's: a cultural history of Taxi Driver, Annie Hall, and Saturday Night Fever. Louisiana: Louisiana State University and Agricultural and Mechanical College, 2005. SARTRE, Jean-Paul. A Náusea. Tradução de Rita Braga. - [Ed. especial]. - Rio de Janeiro: Nova Fronteira, 2011.

SIMMEL, Georg. A metrópole e a vida mental. In: VELHO, Otávio G. (Org.). O fenômeno urbano. Rio de Janeiro: Zahar Editores, 1973.

TAXI Driver. Direção: Martin Scorsese. Produção: Bill Phillips. Intérpretes: Robert de Niro; Jodie Foster; Albert Brooks; Harvey Keitel; Leonard Harris; Peter Boyle; Cybill Shepherd e outros. Roteiro: Paul Schrader. Música: Bernard Herrman. Nova York: Columbia Pictures, 1976. 1 DVD (114 min), son., color., $35 \mathrm{~mm}$.

VOLOCHÍNOV, V. N. (1925-1930). A construção da enunciação e outros ensaios. Tradução de João Wanderley Geraldi. São Carlos: Pedro \& João, 2013. VOLOSHINOV. (1930). Estrutura do enunciado. Tradução de Ana Vaz para fins didáticos. Mimeo. (s/a).

VOLOSHINOV, V. N.; BAKHTIN, M. M. (1926). Discurso na vida e discurso na arte (sobre a poética sociológica). Tradução de Carlos Alberto Faraco e Cristovão Tezza, 1976. 